\title{
Simulation Study on Fracturing with High Temperature Fracturing Fluid in Low Mobility Tight Oil of Xinjiang Oilfield
}

\author{
Liu Li-feng ${ }^{1, a}$,Ran Qi-quan ${ }^{1, b}$,Wang Xin ${ }^{2, c}$ and Chen Fu-li ${ }^{1, d}$ \\ ${ }^{1}$ PetroChina Research Institute of Petroleum Exploration \& Development, Beijing 100083, China \\ ${ }^{2}$ Sinopec Research Institute of Petroleum Exploration\& Production, Beijing 100083, China \\ aliulifeng86@petrochina.com.cn, ${ }^{b}$ hasyllf@163.com, ${ }^{c}$ wangxin.syky@sinopec.com, \\ ${ }^{\mathrm{d}} \mathrm{cfl} 2000 @$ petrochina.com.cn
}

Keywords: Changji tight oil, productivity, factor analysis, numerical simulation

Abstract. The tight oil of Changji in Xinjiang oil field is one of these typical tight oil blocks in China, and it has the characteristics of high viscosity and low fluidity. The change of viscosity of oil is greatly affected by temperature in Changji tight oil. It will cause cold damage to the reservoir and affect the fracturing effect using large volume horizontal well fracturing in this area because of the temperature effect of fracturing fluid. But there is still no study on the cold damage effect of fracturing fluid on reservoir. By means of reservoir numerical simulation, the actual oil well parameters are used to simulate the fracturing and development process of oil wells in this paper, and the stimulation effect of fracturing wells after fracturing with different temperatures is also analyzed. The simulation results show that the variation of fracturing fluid temperature has a great influence on the reservoir range of artificial fracture $2.5 \mathrm{~m}$, and the increase of fracturing fluid temperature can effectively increase the initial production of oil wells.

\section{Introduction}

With poor reservoir property and high oil viscosity (17.1 67.2cp under formation conditions), the tight oil of Changji in Xinjiang oil field belongs to the low mobility type tight oil ${ }^{[1-4]}$. The viscosity curves of crude oil measured in laboratory experiments changed greatly and the viscosity increased rapidly with the decrease of temperature. In hydraulic fracturing, the pumping of normal temperature fracturing fluid will lead to oil thickening, wax deposition and other reservoir cold damage problems ${ }^{[6-}$ ${ }^{8]}$, and fracturing effect is not ideal. In the present literature, the simulation of tight oil development does not take into account the effect of fracturing fluid on reservoir cold damage ${ }^{[9-11]}$, and it is difficult to evaluate the effect of cold damage on tight oil production. In view of this situation, the numerical simulation method was used to compare and analyze the effect of different temperature fracturing fluid on the production efficiency, and the feasibility of high temperature fracturing fluid technology in the development of Xinjiang tight oil was studied.

\section{Numerical model of tight oil fracturing wells}

Using the JHW3 well of Changji tight oil production well in Xinjiang oil field as the simulation object, and actual fracturing parameters, horizontal well parameters and fracturing parameters are used to simulate the whole process of fracturing, flowing back and production. In the fracturing simulation, the actual pumping rate, fracturing fluid volume and the fracturing fluid viscosity were used. Seventeen artificial fractures were set up in advance, and the fracturing process was simulated by switching the perforating at all sections to simulate the seventeen fractures. By this method, the pressure field, 
temperature field and fluid saturation field can be obtained accurately. Then on this basis, the production of oil well was simulated. Simulation parameters are shown in table 1.

TABLE 1 MODEL PARAMETER

\begin{tabular}{|c|c|c|c|}
\hline Parameters & value & Parameters & value \\
\hline Reservoir size $(\mathrm{m})$ & $2000 \times 700 \times 50$ & Number of fracturing segments & 17 \\
\hline Original formation pressure $(\mathrm{MPa})$ & 37 & Interval of fracture $(\mathrm{m})$ & 75 \\
\hline Formation crude oil viscosity $(\mathrm{mPa} \cdot \mathrm{s})$ & 11 & fracturing fluid volume $/ \mathrm{stage}^{3}\left(\mathrm{~m}^{3}\right)$ & 710 \\
\hline Formation temperature $\left({ }^{\circ} \mathrm{C}\right)$ & 85 & Surface temperature $\left({ }^{\circ} \mathrm{C}\right)$ & 20 \\
\hline Reservoir depth $(\mathrm{m})$ & 3030 & pumping rate $\left(\mathrm{m}^{3} / \mathrm{min}\right)$ & 6 \\
\hline Average porosity $(\%)$ & 10 & Fracturing fluid viscosity $(\mathrm{mPa} \cdot \mathrm{s})$ & 160 \\
\hline Average permeability $\left(\times 10^{-3} \mu \mathrm{m}^{2}\right)$ & 0.01 & fracture half length $(\mathrm{m})$ & 110 \\
\hline Initial water saturation $(\%)$ & 20 & $\begin{array}{c}\text { Viscosity of fracturing fluid after } \\
\text { fracturing }(\mathrm{mPa} \cdot \mathrm{s})\end{array}$ & 8 \\
\hline
\end{tabular}

In order to ensure the accuracy of the simulation parameters, the production history of JHW3 well should be fitted. Fitting results are shown in figure 1.

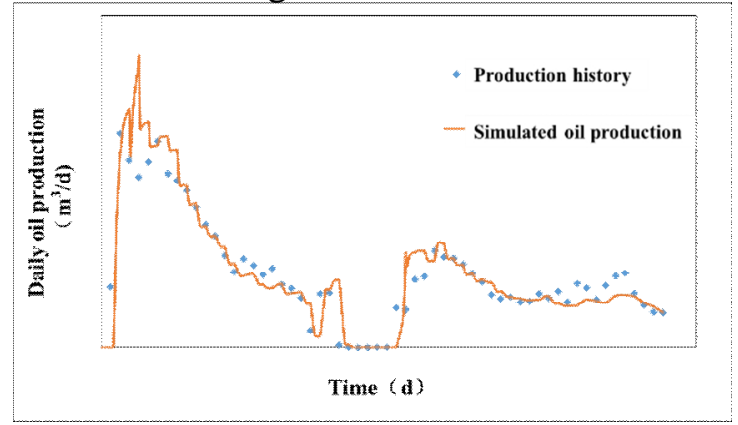

Fig. 1 Fitting results of daily oil production

According to the simulation results, the simulation parameters accord with the actual production. On the basis of this basic model, the fracturing effect simulation calculation and evaluation of different temperature fracturing fluids were carried out.

\section{Influence of fracturing fluid temperature on oil well development}

Keep other parameters of the model unchanged, and carry out Fracturing simulation of fracturing fluid with temperature of $20^{\circ} \mathrm{C} 、 80^{\circ} \mathrm{C} 、 140^{\circ} \mathrm{C} 、 200^{\circ} \mathrm{C}$. Shut down well for 2 days after fracturing, and flow back with a bottom-hole pressure of $29 \mathrm{MPa}$. In order to prevent the initial flow back velocity is too large, and a large amount of initial proppant backflow, the daily discharge limit as $120 \mathrm{~m} 3 / \mathrm{d}$.

\section{Effect of fracturing fluid temperature on formation temperature}

The most direct influence of fracture fluid temperature is the temperature near the artificial fracture. With the increase of fracturing fluid temperature, the temperature of reservoir near artificial fracture will rise. Simulating the variation of temperature field of artificial fracture and near fracture zone by using different temperature fracturing fluid. Calculated results are shown in figure 2-5. 


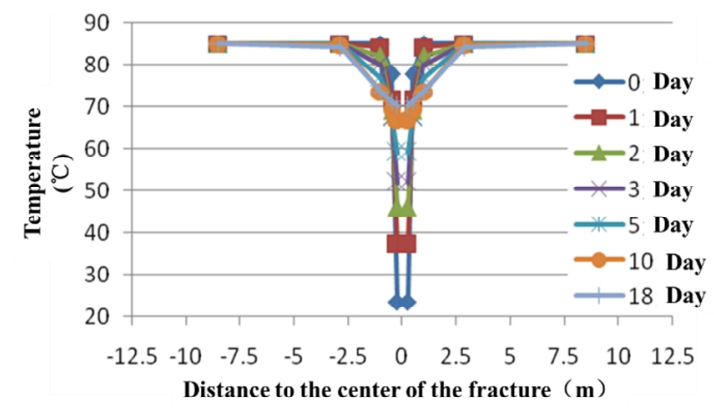

Fig. 2 Temperature variation with time using $20^{\circ} \mathrm{C}$ fracturing fluid

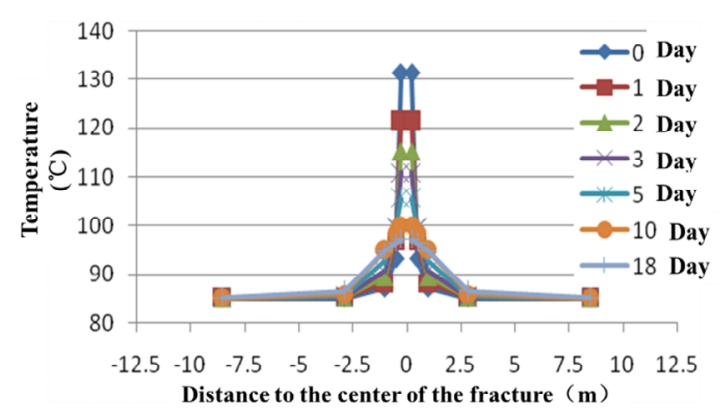

Fig. 4 Temperature variation with time using $140^{\circ} \mathrm{C}$ fracturing fluid

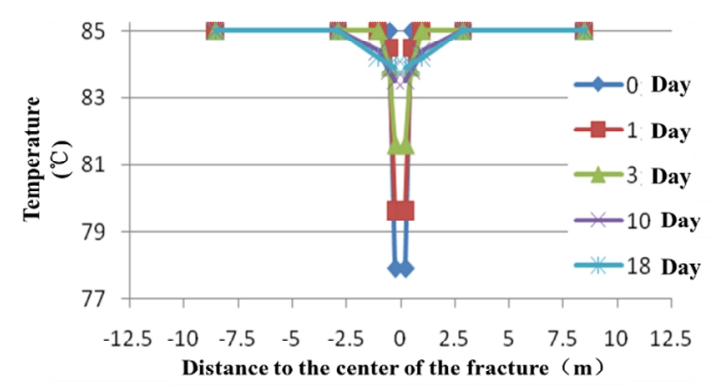

Fig. 3 Temperature variation with time using $80^{\circ} \mathrm{C}$ fracturing fluid

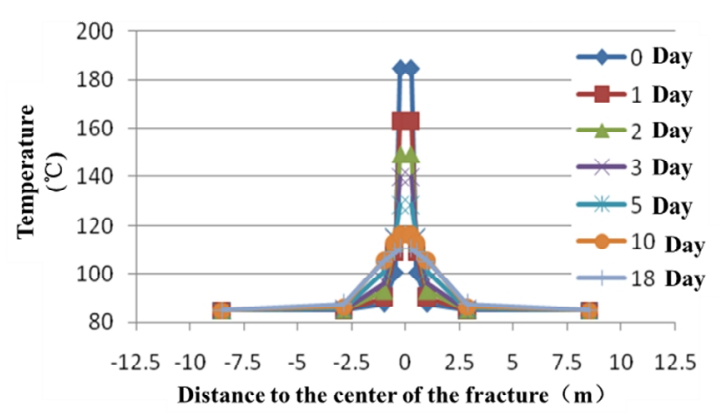

Fig. 5 Temperature variation with time using $200^{\circ} \mathrm{C}$ fracturing fluid

Because the original temperature of the formation is $85^{\circ} \mathrm{C}$, when the injected fracturing fluid temperature is less than $85^{\circ} \mathrm{C}$, the temperature of the reservoir around the fracture will be reduced, and When the fracturing fluid temperature is greater than $85^{\circ} \mathrm{C}$, the temperature of the reservoir around the fracture will be increased. The simulation results show that the fracturing fluid temperature is more obvious in the range of $2.5 \mathrm{~m}$ reservoir around the fracture.

\section{Effect of fracturing fluid temperature on viscosity of crude oil}

The change of reservoir temperature will directly affect the viscosity of crude oil. Crude oil viscosity is one of the key parameters affecting oil well productivity. According to the results of laboratory tests, the viscosity temperature relationship of Xinjiang tight oil is shown in figure 6 , the viscosity temperature curve was obtained by regression of the data points, and the simulation study was based on this curve.

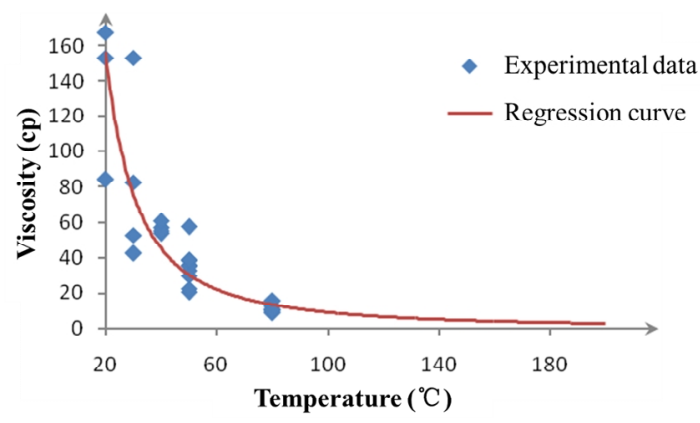

Fig. 6 Viscosity-temperature relationship of tight oil in Xinjiang 
The calculation results of the effect of different temperature fracturing fluid on crude oil viscosity are shown in figure $7-10$.

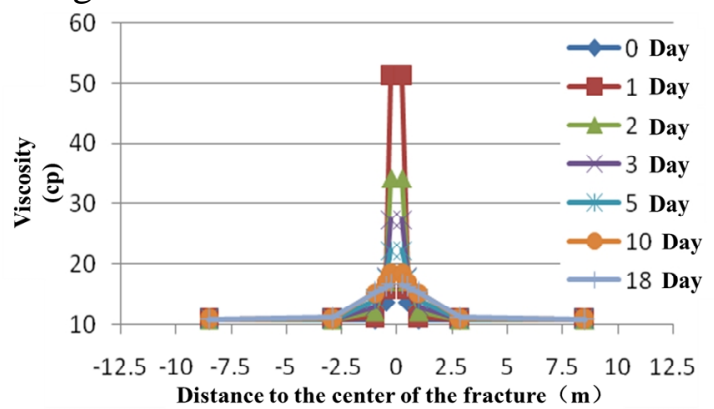

Fig. 7 Variation of viscosity with time using $20^{\circ} \mathrm{C}$ fracturing fluid

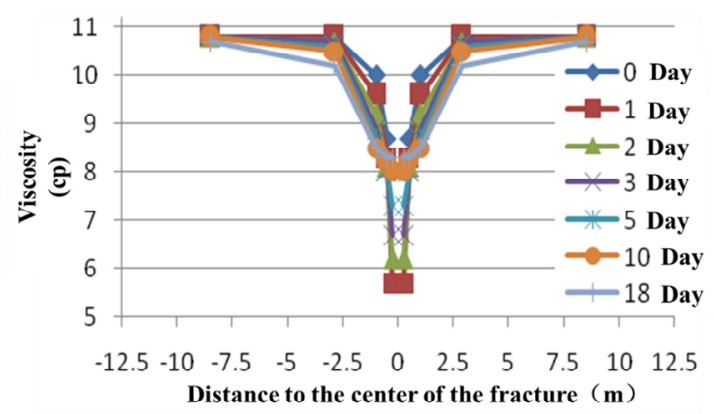

Fig. 9 Variation of viscosity with time using $140^{\circ} \mathrm{C}$ fracturing fluid

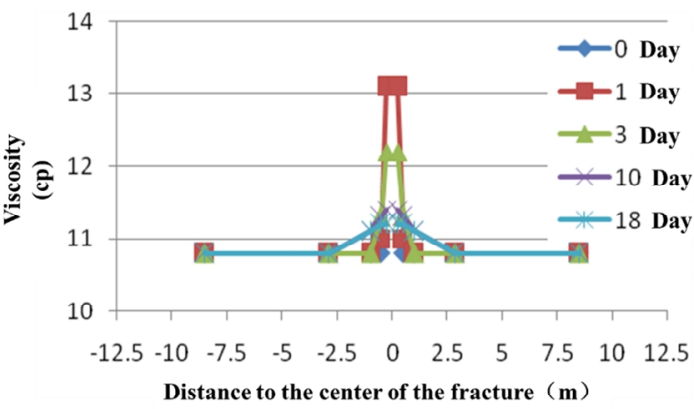

Fig. 8 Variation of viscosity with time using $80^{\circ} \mathrm{C}$ fracturing fluid

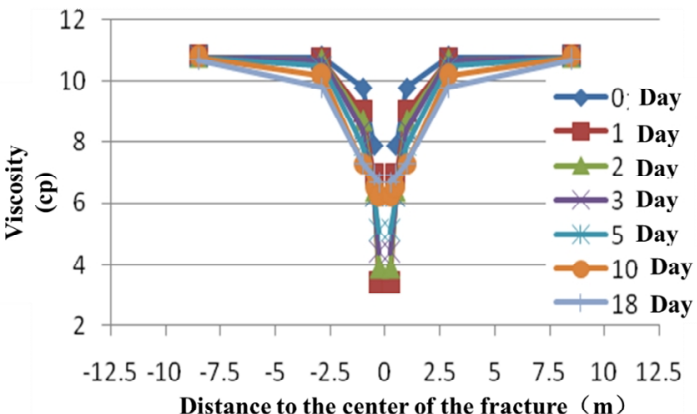

Fig. 10 Variation of viscosity with time using $200^{\circ} \mathrm{C}$ fracturing fluid

From the calculation results, it can be found that the influence of the fracturing fluid temperature on the viscosity of crude oil is obvious. The viscosity of crude oil can be reduced from 50CP to 3CP when the fracturing fluid temperature is increased from $20^{\circ} \mathrm{C}$ to $200^{\circ} \mathrm{C}$. In addition, with the extension of shut in time, the temperature inside the fracture gradually restored to the initial formation temperature, showing a rapid recovery in the early stage and a slow trend.

\section{Effect of fracturing fluid temperature on oil well production}

The final result of simulation calculation is the output of oil well, the calculated results of oil production after fracturing hydraulic fracturing at different temperatures are shown in figure 11-12.

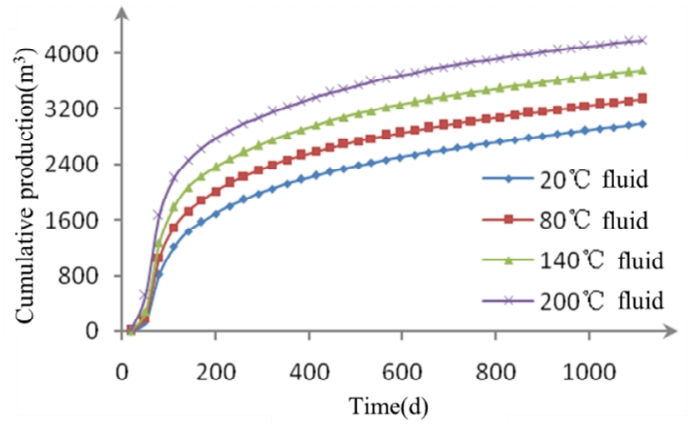

Fig. 11 Cumulative oil production curve

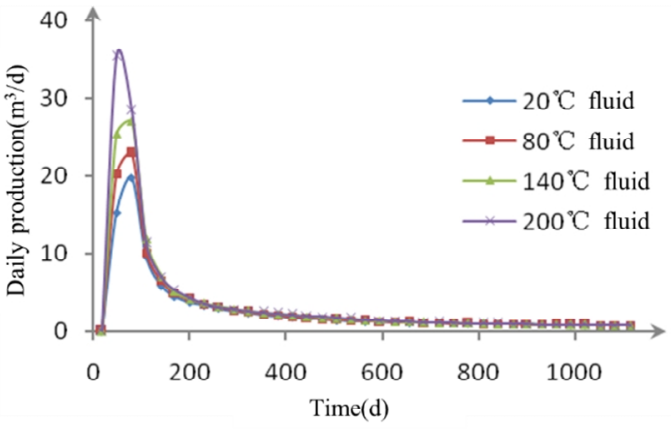

Fig. 12 Daily oil production curve

As can be seen from figure 11, the oil production increases with the increase of fracturing fluid temperature. Figure 12 shows that with the increase of injection fracturing fluid temperature, the early 
oil production increased significantly, fracturing fluid temperature reached $200^{\circ} \mathrm{C}$ peak oil production increased by nearly double the temperature of $20^{\circ} \mathrm{C}$ 。 But with the increase of time, the daily output of oil is gradually reduced, and the higher the fracturing fluid temperature, the faster the output decreases. After 3 months of oil production, the daily oil production of different temperature fracturing fluid tends to be consistent.

\section{Conclusions}

In this paper, a practical production well is used to simulate the fracturing and production process of oil wells with different fracturing fluid temperatures. The following main conclusions are obtained:

The temperature of fracturing fluid has a great influence on the temperature of artificial fracture and reservoir around the fracture and viscosity of crude oil. With the increase of temperature, the viscosity of oil decreases obviously, but the influence range is limited, mainly in the range of $2.5 \mathrm{~m}$ around the fracture.

With the increase of injected fracturing fluid temperature, the increase of oil production rate increases obviously. In the early production period, the increase of oil production is the biggest, and with the extension of production time, the increase of oil production gradually decreases. Therefore, the use of high temperature fracturing fluid technology can effectively improve the production of tight oil wells in Xinjiang.

\section{Acknowledgements}

This work was financially supported by the National Science and Technology Major Project of the Ministry of Science and Technology of China (Grant No. 2016ZX05046-003).

\section{References}

[1] Qiu Zhen, Li Jianzhong, Wu Xiaozhi, et al. Exploration status, main geologic characteristics and their differences of tight oil between America and China. Lithologic Reservoirs, 2015, 27 (4): 119126.

[2] Kuang Lichun, Tang Yong, Lei Dewen, et al. Formation conditions and exploration potential of tight oil in the Permian saline lacustrine dolomitic rock, Junggar Basin, NW China. Petroleum Exploration and Development, 2012, 39 (6): 657 667.

[3] Pang Zhenglian, Zou Caineng, Tao Shizhen, et al. Formation distribution and resource evaluation of tight oil in China. China Engineering Science, 2012, 14 (7): 60 67.

[4] WU Chengmei, GUO Zhineng, TANG Fuping, et al. Early Exploitation Characteristics of Lucaogou Tight Oil of Permian in Jimusaer Sag, Junggar Basin. XINJIANG PETROLEUM GEOLOGY, 2014, 35 (5): 570 573.

[5] Zou Caineng, Yang Zhi, ZHU Rukai, et al. Progress in China's Unconventional Oil \& Gas Exploration and Development and Theoretical Technologies. Acta Geologica Sinica, 2015, 89(6):979 1007.

[6] Economides, M.J, Nolte, K.G. Reservoir Stimulation. Petroleum Industry Press, 2002.

[7] Yao Kai, Jiang Hanqiao, Dang Longmei, et al. Mechanism of Cooling Damage to Highpour-point Oil Reservoir. Journal of China University of Petroleum, 2009, 33(3):95-98.

[8] Kumar S, Kumar P, Tandon R, etal. Hot Water Injection Pilot: A Key to the Waterflood Design for the Waxy Crude of the Mangala Field. International Petroleum Technology Conference, 2008.

[9] Germanovich, L.N. and Astakhov, D.K. Fracture closure in extension and mechanical interaction of parallel joints. Journal of Geophysical Research. 2004, Vol. 109, B02208 published 24 February. 
[10]Bazan, L.W, Lattibeaudiere, M.G, and Palisch, T.T, Hydraulic Fracture Design and Well Production Results in the Eagle Ford Shale: One Operator's Perspective, Paper SPE 155779, 2012.

[11]Meyer, B.R, and Bazan, L.W, A Discrete Fracture Network Model for Hydraulically Induced Fractures: Theory, Parametric, and Case Studies, Paper SPE 140514 , 2011. 